\title{
Process Visualization and Diagnostic Models Using Real Time Data of Blast Furnaces at Tata Steel
}

\author{
Adity GANGULY, A. Srinivas REDDY and Ashok KUMAR \\ Ironmaking Technology Group, Tata Steel, Jamshedpur, PIN-831005 India. E-mail: adity.ganguly@tatasteel.com
}

(Received on November 2, 2009; accepted on April 30, 2010)

\begin{abstract}
Real time data warehousing, process visualization and data based modeling are the basis of any diagnosis carried out in iron making area of Tata Steel. Large volume of data generated during the making of coke, sinter and iron are being archived along with quality and performance data in a central data repository. These data is being constantly used by analyst to diagnose process disturbances and also to optimize various process and consumption parameters. To squeeze out greater level of information from the data, various process models are constantly being developed. These models are of various types. Few are based on simple mass balance where as others are empirical or statistical diagnostic model based on on-line measurements. Some are visualization models where large numbers of data are organized and given a form which can be better visualized by the analyst. Some of such models developed for in-depth analysis of blast furnace like 'cohesive zone model,' 'hearth liquid level monitoring' etc. are described in this paper. Mainly the brief development process and applications in process analysis of each models have been described here.
\end{abstract}

KEY WORDS: data warehouse; process models; staves temperature visualization; cohesive zone; hearth liquid level; process disturbances, diagnosis.

\section{Introduction}

In iron making division of Tata Steel, Jamshedpur, 8 blast furnaces, 4 coke plants and 4 sinter plants are in operation. There is a mix of new state of the art plants and old plants having less automation and lots of manual operation. These are of various sizes and having a mix of different kind of equipments e.g. the charging system of blast furnaces itself includes variety of equipments like GIMBAL top, Bell less top and double bell supplied by various manufactures. Three of the furnaces use coal tar as an injectant while others use pulverized coal injection. Among four coke plants, one uses top charge technology, two others are based on stamp charge technology and the recent plant uses heat recovery method of coke making. The other unique feature is the indigenous raw materials used by iron making division of Tata Steel which are of inferior quality that the most of the other plants of the world use.

Along with all the complexities mentioned above remains the demand of increasing productivity along with the need for optimization of raw materials and energy usage maintaining the cost competitiveness of Tata Steel. The whole situation makes the work of process analyst very demanding and challenging. The continuous monitoring of the process for diagnosis of disturbances and improvement was imperative and so a data platform was thought of which will seamlessly integrates data from various disparate platforms and will make analysis much easier and quick and informed decision can be made.

In view of above a data warehouse was built named 'iMonitor' which contains data of last many years. This large scale database is helping in efficiently visualizing and analyzing the iron making processes. Various empirical and statistical models have also been built to understand the infurnace phenomenon. In this paper the data acquisition process visualization and modeling of blast furnaces has been described.

\section{Iron Making Data Warehouse}

The schematic of the data warehouse named 'iMonitor' is shown in Fig. 1.

\subsection{Data Acquisition}

The vast database of iMonitor holds process and quality data of Coke, Sinter and Iron making plants of Tata Steel. This database is linked to all plants mentioned above by means of high speed LAN connectivity and pulls data from various process computers of these plants. The data acquisition from 8 nos. of blast furnaces is as follows.

Each of the furnaces is having different level-I systems, data collectors, process computers supplied by different manufacturers. The collectors collect process data from various process instruments and sensors at a predefined frequency. Collected data are then stored in process computers of each furnaces for a limited time period in the proprietary database unique to each supplier. iMonitor collects data from each such computers at every $5 \mathrm{~min}$ intervals and store it in database. Various interfacing programs developed to collect data from different platforms and integrating it in one database. Along with the process data, input raw material quality data and output hot metal quality data are col- 


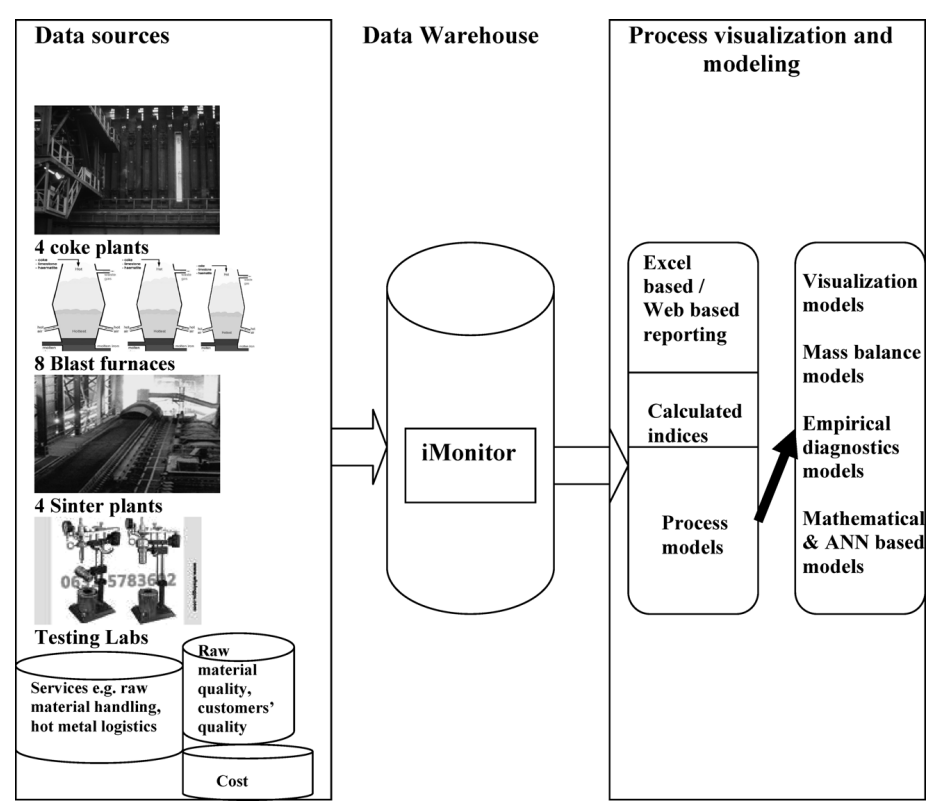

Fig. 1. Schematic representation of data warehouse and process visualization system of iron making area at Tata Steel, Jamshedpur.

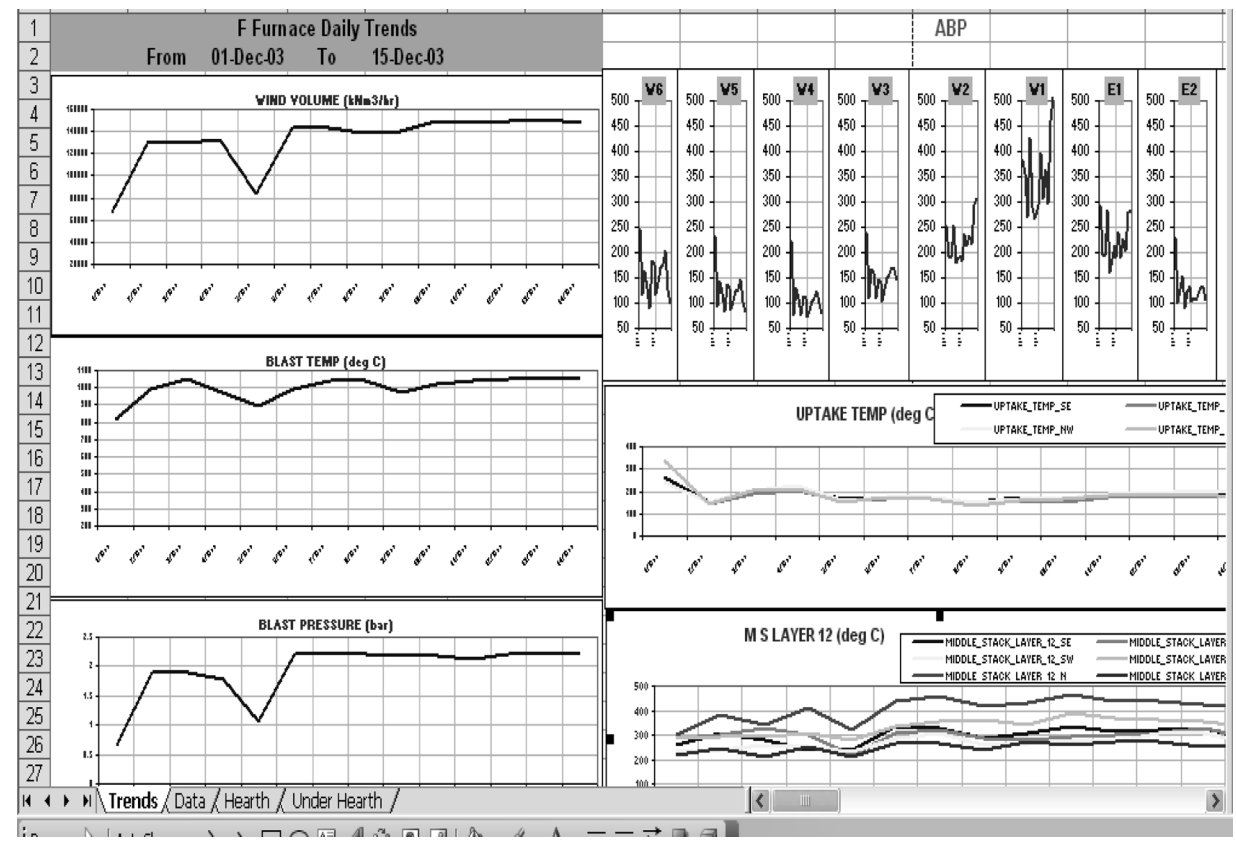

Fig. 2. Excel based customized trends of a blast furnace.

lected from lab computers. For capturing casting and iron and slag tapping related data, data entry screens have been provided to cast house operators as automation system is not adequate in all furnaces.

Large volume of data thus accumulated is organized in a suitable manner so that it is easily retrievable from any computer connected to company's local area network via intranet. Data compiled every $5 \mathrm{~min}$ are aggregated every hour, every day, every week, every month according to the purpose for which they are used.

\subsection{Process Visualization}

The iMonitor system uses two different platforms for data visualization-client based front-ends and web based front ends. The client based front end is mostly used by the user and the application developed uses suitable drivers and query builders for downloading data from the iMonitor to the analysis platform. For the benefit of the process analyst, customized trends have been made but one has the flexibility to manipulate and trend the data in any fashion using basic knowledge of querying and trending. One example of customized graphs is shown in Fig. 2.

Using the base data form the various sensors, various calculated indices have been configured e.g. the $\mathrm{H}$ furnace is having 12 above burden probe temperatures. To visualize the effect of these temperatures, three indices, central working index (CWI), peripheral working index (PWI) and middle working index (MWI) are being calculated which gives an indication of gas flow pattern in the furnace. Other indices like solution loss carbon, deadman cleanliness index, ore layer thickness, coke layer thickness, tuyere velocity etc. are also being calculated and stored in the database. 


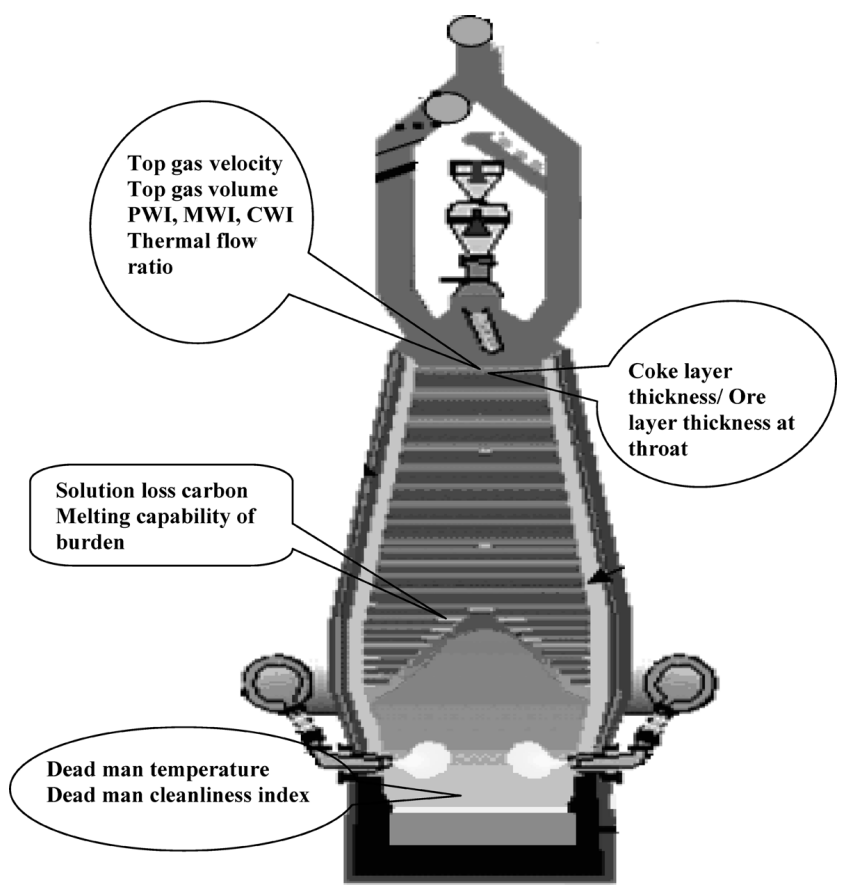

Fig. 3. Some calculated indices configured in iMonitor to explain furnace behavior better.

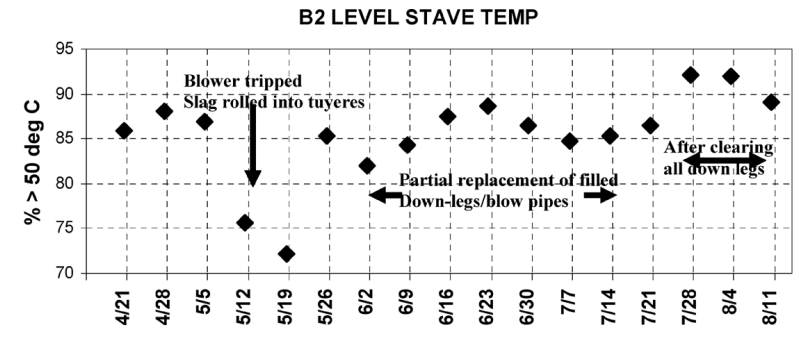

Before blower trip (stave temperatures okay, most temperature above $50^{\circ} \mathrm{C}$ )
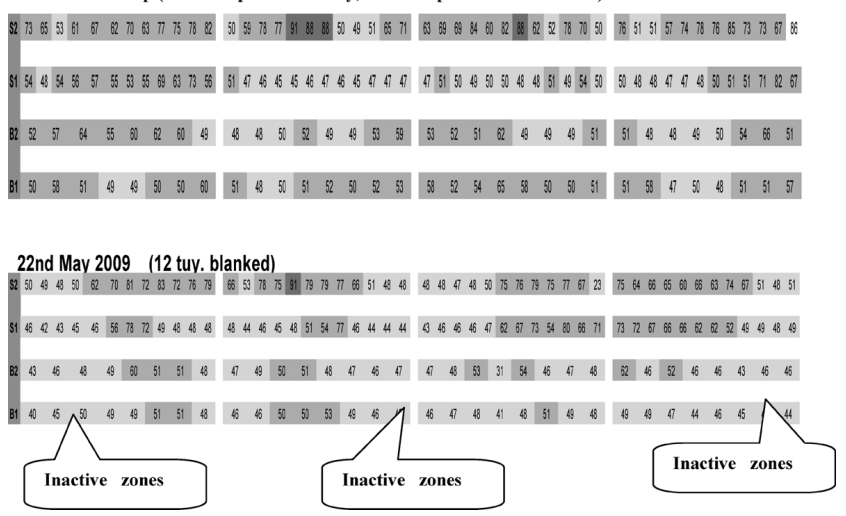

Fig. 5. Use of stave visualization model to assess the wall activity in one of breakdown event of a blast furnace.

BF ' $G$ ': Changes in coke quality (\& hearth condition)

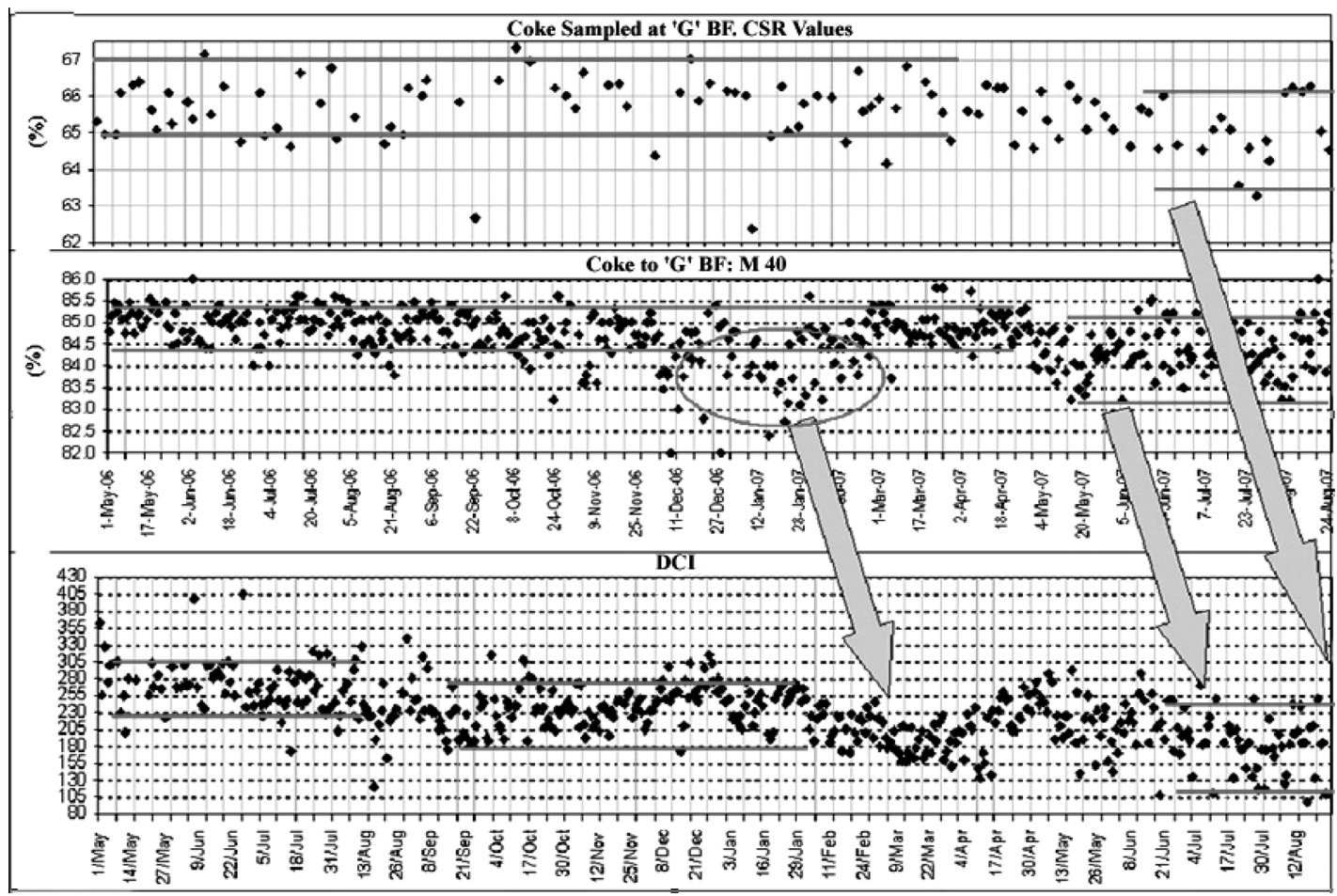

Fig. 4. Impact of poor coke quality on the dead man cleanliness index (DCI) of blast furnace hearth.

The heat fluxes and heat losses at various parts of the furnaces are also being calculated. Various such indices configured in iMonitor are shown in Fig. 3.

Use of one such calculated index in the process analysis is shown in Fig. 4. Change in the dead man cleanliness index along with poor coke quality is depicted in the following graphs.

\section{Visualization Model of Stave Temperatures ${ }^{1)}$}

Stave temperature in blast furnaces assists in diagnosis of reasons for lower heat fluxes and activities at the wall. Being a tall structure, several hundreds thermocouples are inserted at various level to understand the condition of stack. Not all the sensors are placed at equal intervals. In 


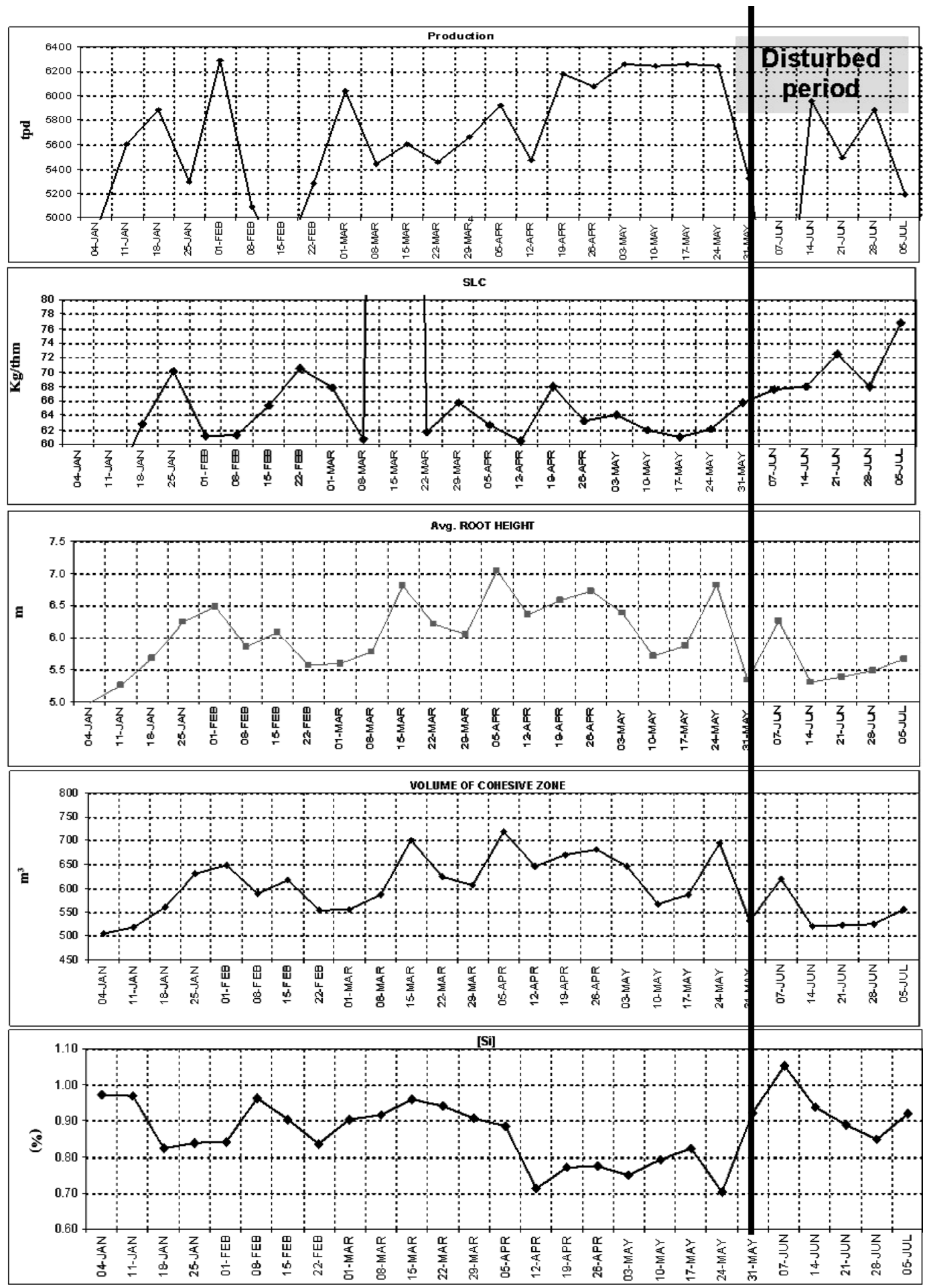

Fig. 6. Output of cohesive zone model used to diagnose a particular blast furnace disturbance.

the stave visualization model, these large amounts of data have been organized in a manner to give useful information about furnace behavior to the process analyst.

The outer profile of the furnace was opened up and projected onto two dimensional planes in vertical and horizontal directions to display the measured temperatures. The vertical axis represents the height and horizontal axis represents the furnace diameter. Each block represents one sensor and the temperature of the sensor is displayed along with its severity depicted by different colours. The constant updating of visual information helps to visualize the nonsteady phenomenon of blast furnaces.
The model with the example of an application case is shown in Fig. 5. In one of the big blast furnace, a breakdown happened due to blower trippage and slag rolled into the tuyerse. Furnace was in operation with some tuyere blanked. The situation of wall activity inside the blast furnace could very well visualize in the stave model. Different phases of recovery were also monitored using the model.

The chronologies of events in terms of dates are shown in the first graph of Fig. 5. The line graph shows the percentage of thermocouples showing more than $50^{\circ} \mathrm{C}$ in one particular level of stave cooling members. Before 10th May, i.e., in normal running condition, the percentage was high 
which is also shown by the first snapshot of the stave model of the figure. After breakdown, furnace ran for quite some time with some tuyere blanked due to slag rolling into the tuyeres. The wall condition for that period is shown in second snapshot of Fig. 5. After shutdown, which was at the beginning of month of august, all tuyeres in operation and so the percentage of thermocouples above $50^{\circ} \mathrm{C}$ also increased.

\section{Empirical and Computational Models}

Apart from complex graphical representations, there are statistical and computational models which help the process experts to understand the in-furnace phenomenon which are otherwise difficult to interpret in absence of direct measurements. One such model is described here.

\subsection{Cohesive Zone Model ${ }^{1,5)}$}

\subsubsection{Model Development - Initial Approach}

The model calculates the cohesive zone root position and shape using the vertical stack temperatures and above burden probes of furnaces. The shape and location of cohesive zone decides the gas flow distribution. The first few coke slits in cohesive zone divert the hot upcoming gas in lower portions towards the wall which increases the temperature near the wall. Therefore, if the root of cohesive zone shifts in furnace, the gas passing through these coke slits will change accordingly. The result will be that the furnace stack temperatures distribution will change with this varying gas volume distribution. The model tries to analyze the temperature pattern to deduce position of the root mathematically.

The change in temperature distributions is being tracked by calculating correlation coefficient of stack temperatures of two consecutive stack levels. When the direction of coefficient is found to be negative for the first time between two levels the root is assumed to be midway between these two stack levels.

\subsubsection{Modified Approach with Higher Level Techniques}

With the phase I of development, the model was calculating the cohesive zone root height quite well in the smaller furnaces with refractory cooling where temperature difference between stack levels are of the order of 30 to $40^{\circ} \mathrm{C}$. For bigger furnaces with copper stave cooling (temperature difference 5 to $8^{\circ} \mathrm{C}$ ) only 30 to $40 \%$ of sectors the output was being generated.

To further improve the output of the model, an advanced statistical technique, principal component analysis (PCA) has been used to find out the position of changeover of temp distribution. This tool is applied in the model when no result is obtained in the first step of analysis i.e. the correlation matrix.

The various outputs of the cohesive zone model are the sector wise root height of cohesive zone, the peak height of cohesive zone and the lopsidedness of cohesive zone and the volume of dripping zone.

\subsection{Application Case}

During one of the experiment of 3 batch charging conducted in one of the blast furnace, attempt to remove bottle- neck the charging capacity, Wall gas flow significantly suppressed due to coke scooping which was a result of increased flow rate. Melting capacity index came down drastically. During that time the model output showed cohesive zone root height decreased and the volume of dripping zone reduced. The phenomenon is depicted in the graphs of Fig. 6.

\section{Hearth Liquid Level Monitoring ${ }^{3)}$}

Hearth of a blast furnace is a receptacle for temporary storage of liquid (metal and slag) generated in the blast furnace. The hearth is filled up with coke and only $30-35 \%$ of the total volume is available as void for liquids. It is understood that an abnormally higher level of retained liquids may not only destabilize the process by affecting permeability of lower part of the furnace but may also lead to slag rolling into the tuyeres and/or tuyeres losses.

Hence the quantum of liquid with in the hearth at any instant is a vital parameter to be monitored. The direct measurement of the above is very difficult due to hostile nature of the hearth ambience and hence estimation of hearth liquid level at any instant was done using various indirect measurements.

Higher level of liquid within the hearth may possibly be an outcome of mismatch between generation rate and drainage rates, delayed slag appearance or delayed cast opening. Based on the above understanding a mathematical model based on empirical formulations was developed to estimate the level of the metal, slag and the combined height within the hearth. The instantaneous production rates are being calculate using raw material charging and also using oxygen flow based on some applicability criterion. The metal and slag drainage rates are being obtained using the information captured by cast house operators and various on-line measurements. The visual web based display of the model to the operators of blast furnaces and the output of the model explained in graphical form from start
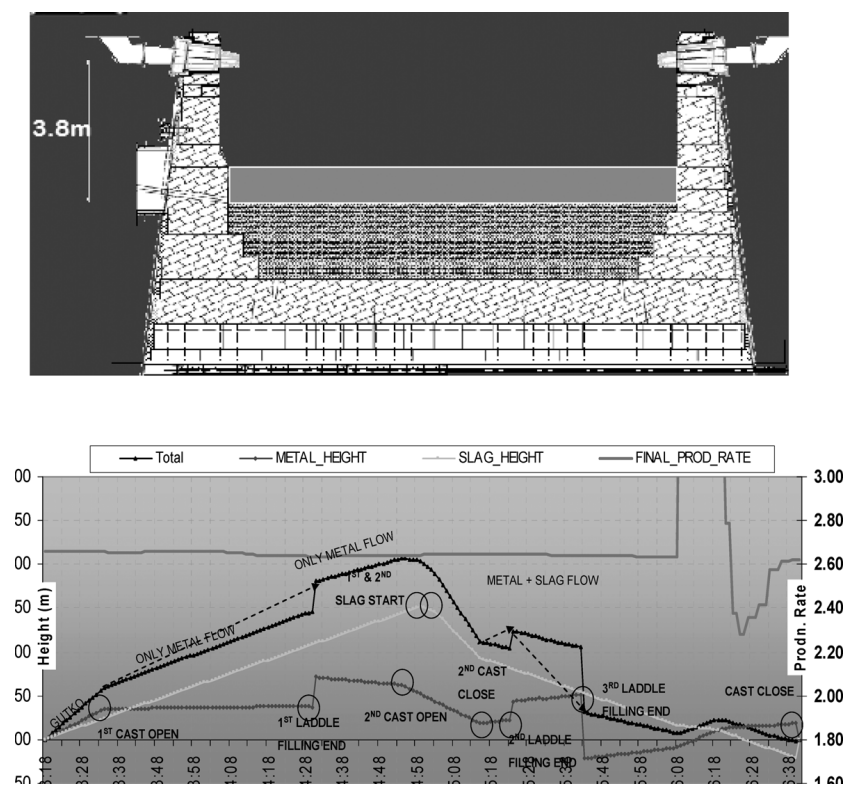

Fig. 7. Web based visual display of the model and output of model, slag and metal height, depicted for a particular cast. 

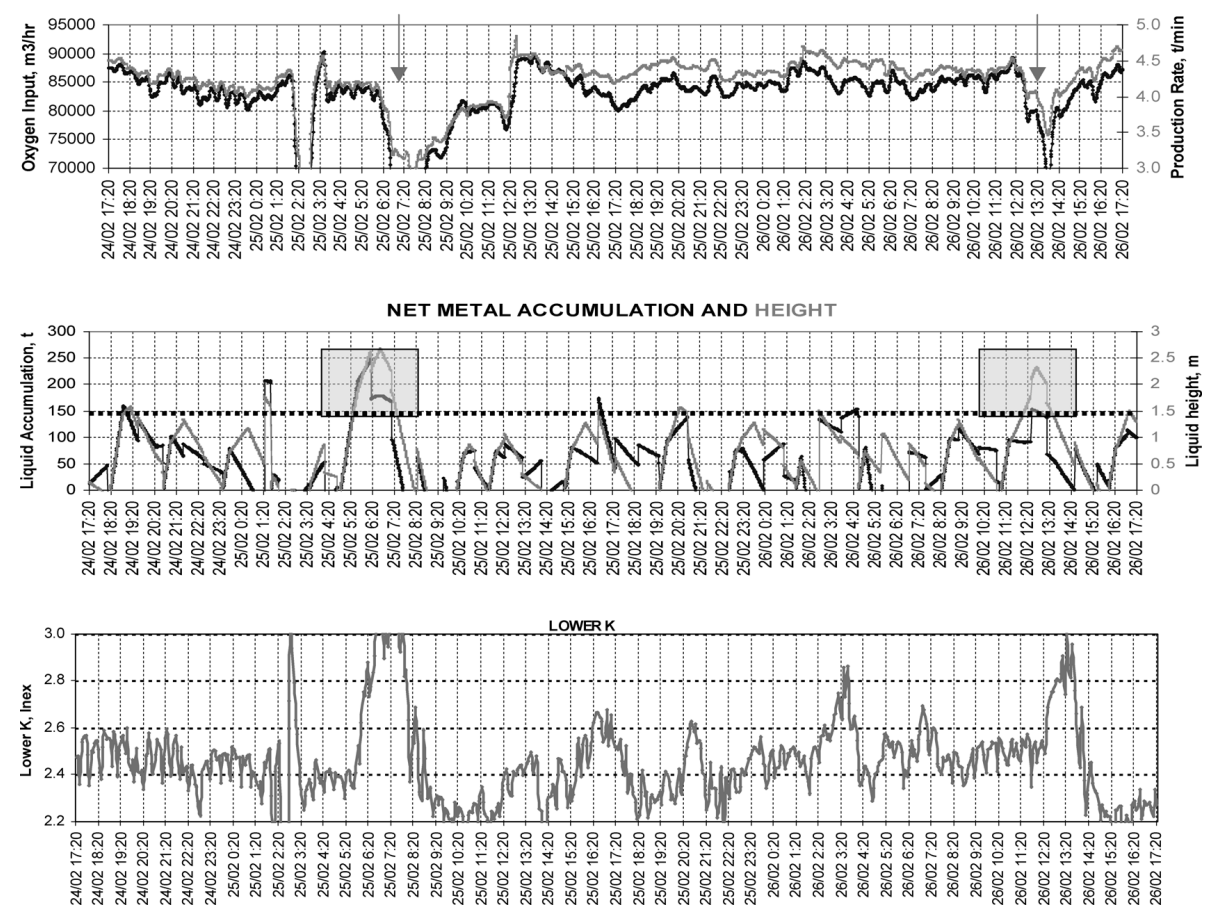

Fig. 8. Output of the hearth liquid level model used for operatorís decision making.

to end of cast is shown in Fig. 7.

The out put model assists the operator to take decisions on parallel tapping or production rate cuts as may be necessary.

The graphs given in Fig. 8 show an example. Graph shows the rise in the liquid level (model output) along with increase of resistance of lower part permeability of the furnace and consequently operators lowered the production rates.

\section{Conclusion}

The data acquisition, development of new models and tuning of the existing model are the continuous activities. The special feature of these models is that these are simplistic models yet very effective and are able to explain inside phenomenon of the blast furnaces very well. These models are being extensively used to explain various process disturbances. At present most of the models are being used for post-mortem analysis. Efforts for developing predictive model using artificial intelligent techniques ${ }^{2)}$ are on. Some of the future works are development of shaft efficiency model, development of slip/hanging prediction model.

\section{REFERENCES}

1) S. Matsuzaki, M. Ito, M. Naito, M. Isobe and K. Kakiuchi: ISIJ Int., 45 (2005), 1452.

2) H. Saxen, L. Lassus, M. Seppanen and T. Karjalahti: Ironmaking Steelmaking, 27 (2000), 207.

3) J. Brannbacka and H. Saxen: ISIJ Int., 45 (2001), 1131.

4) X. Bi, K. Torssell and O. Wijk: ISIJ Int., 32 (1992), 481

5) A. Ganguly, R. Kumar, A. Kumar and A. Upadhyaya: Tata Search, 1 (2007). 